OPEN ACCESS

Edited by:

Ana Sandoval-Rodriguez, University of Guadalajara, Mexico

Reviewed by:

Jingying Zhou,

The Chinese University of Hong

Kong, China

${ }^{*}$ Correspondence:

Ming Yang

yangmin@health.missouri.edu

Specialty section:

This article was submitted to

Gastroenterology,

a section of the journal

Frontiers in Medicine

Received: 05 October 2021

Accepted: 28 October 2021

Published: 18 November 2021

Citation:

Zhang C and Yang M (2021) Targeting

$T$ Cell Subtypes for NAFLD and

NAFLD-Related HCC Treatment: An

Opinion. Front. Med. 8:789859.

doi: 10.3389/fmed.2021.789859

\section{Targeting T Cell Subtypes for NAFLD and NAFLD-Related HCC Treatment: An Opinion}

\author{
Chunye Zhang ${ }^{1}$ and Ming Yang ${ }^{2 *}$ \\ ${ }^{1}$ Department of Veterinary Pathobiology, University of Missouri, Columbia, MO, United States, ${ }^{2}$ Department of Surgery, \\ University of Missouri, Columbia, MO, United States
}

Keywords: T cell subpopulation, NAFLD, HCC, treatment, cytokines, chemokines

\section{INTRODUCTION}

The increasing prevalence of non-alcoholic fatty liver disease (NAFLD), as well as its advanced stage non-alcoholic steatohepatitis (NASH) with the progression of liver inflammation and cell death with or without hepatic fibrosis, brings a heavy burden to public health (1). Non-alcoholic fatty liver disease is commonly associated with the incidence of obesity and diabetes $(2,3)$. In the United States, the prevalence of obesity raised from 30.5 to $42.4 \%$ from years $1999-2000$ to years 2017-2018 as the Centers for Disease Control and Prevention (CDC) reported, and the prevalence of severe obesity also increased from 4.7 to $9.2 \%$ at this period. Recently, a new nomenclature of NAFLD, metabolic associated fatty liver disease (MAFLD), was recommended, which is thought to be more accurate to reflect the clinical pathogenesis of this disease with metabolic dysfunction $(4,5)$. There is no appropriate treatment for NAFLD up to date, except for early prevention via change of lifestyle $(2,6)$. Understanding the cellular and molecular pathogenesis of NAFLD and its relative advanced liver disease is helpful to define new potential targets for treatment.

Hepatic immunity plays a critical role in the pathogenesis of liver diseases $(7,8)$, including NAFLD, NASH, and end-stage of liver disease. Both hepatic innate and adaptive immune cells, as well as their interaction, orchestrate the progression of NAFLD and NASH (9). For example, the accumulation of activated hepatic $B$ cells driven by gut microbiota impacted liver inflammation and fibrosis via modulating both intrahepatic innate and adaptive immunity during the progression of NASH (10). New functions of special types of $\mathrm{T}$ cells are reported to be associated with the progression of NAFLD and hepatocellular carcinoma (HCC) defined by the single-cell RNA sequencing (sRNA-seq) technology $(11,12)$. Here, we mainly focus on the latest investigation of the function of special types of T cells in NAFLD and NAFLD-related primary liver cancer.

\section{FACTORS CAUSING NAFLD AND NAFLD-RELATED HCC PROGRESSION}

Non-alcoholic fatty liver disease is an increasing factor that induces the development of HCC (13). The pathogenesis of NAFLD-related HCC progression remains to be clarified. The causing factors such as genetic factor (e.g., the genetic variant I148M of rs738409 in patatin-like phospholipase domain containing 3, PNPLA3) and epigenetic factors (e.g., histone deacetylase) for NAFLD and NASH may result in liver fibrosis and cirrhosis, and finally leading to the development of HCC (14-17). In addition, several other factors including environmental factors have been identified to be associated with NAFLD-related HCC progression (18), such as lipid metabolism (19), 
and dysregulation of gut microbiota (20). For example, dysregulation of lipid metabolism in NAFLD induced hepatic accumulation of linoleic acid and subsequent loss of $\mathrm{CD}^{+}$ $\mathrm{T}$ cells due to an increase of reactive oxygen species (ROS) (21), resulting in an increased incidence of HCC. Clinical trial studies also showed that anti-programmed death-1 (PD1) or anti-programmed death-ligand 1 (PD-L1) treatment decreased the overall survival (OS) of human patients with $\mathrm{NASH}$-induced HCC compared to non-NASH-induced HCC patients (22). Cellular mechanism study demonstrated that stimulation with gut microbial extracts from NAFLD-related HCC subjects can increase the frequency of regulatory $\mathrm{T}$ cells (Tregs) and decrease the frequency of $\mathrm{CD} 8^{+} \mathrm{T}$ cells in human peripheral blood mononuclear cells (PBMCs), compared to treatment with bacterial extracts from non-NAFLD subjects (20), which indicates an important role of gut microbiota in modulating immunity in HCC microenvironment. In addition, peripheral PBMCs showed an immunosuppressive phenotype in human patients with NAFLD-related HCC compared to nonNAFLD and NAFLD-cirrhosis patients (20). Independent of these discussed causing factors for liver disease, $\mathrm{T}$ cells play an important role in the progression of NAFLD and NAFLD-related HCC. Thus, it is critically important to delicate the function of each subtype of T cells in NAFLD-HCC progression.

\section{FUNCTION OF T CELLS IN NAFLD AND NAFLD-RELATED HCC}

\section{Function of $\mathrm{CD}^{+} \mathrm{T}$ Cells in NAFLD}

LIGHT (tumor necrosis factor superfamily member 14, TNFSF14) expression in activated $\mathrm{CD}^{+} \mathrm{T}$ cells induced by feeding a choline-deficient high-fat diet (CD-HFD) promoted $\mathrm{NASH}$ and $\mathrm{HCC}$ progression in mice via interacting with lymphotoxin- $\beta$ receptor (LT $\beta \mathrm{R}$ ) in hepatocytes $(23) . \mathrm{CD}^{+} \mathrm{T}$ cells were also increased in the livers of obese human patients with NASH and cirrhosis, which was positively correlated with hepatic stellate cell (HSC) activation, evidenced by the increased expression of $\alpha$-smooth muscle actin ( $\alpha$-SMA) (24). In contrast, depletion of $\mathrm{CD}^{+} \mathrm{T}$ cells significantly reduced liver inflammation and HSC activation. A 3.5fold increase of $\mathrm{CD}^{+} \mathrm{T}$ cells with high expression of cytotoxic interleukin (IL)-10 can also be found in obese mice while feeding a western diet (WD) compared to the chow diet (24). High expression of IL-10 may promote the progression of HCC (25). Another study also showed that impairing $\mathrm{CD}^{+} \mathrm{T}$ cell activation in mineralocorticoid receptor (MR)-deficient mice decreased liver steatosis in a methionine-choline deficient diet (MCD)-induced NASH model (26). Tumor development altered fatty acid partitioning in the fatty liver via inhibiting prolyl hydroxylase domain (PHD)3 expression, which results in function loss of cytotoxic $\mathrm{CD}^{+} \mathrm{T}$ cells and impaired anti-tumor function (27). Therefore, enhancing or reversing the role of $\mathrm{CD}^{+} \mathrm{T}$ cells in NAFLD may inhibit NAFLD-HCC progression. Here, we summarize some specific subpopulations of $\mathrm{CD}^{+} \mathrm{T}$ cells in NAFLD-related HCC.

\section{Function of CD8 ${ }^{+} \mathrm{T}$ Cells in NAFLD-Related HCC $\mathrm{PD} 1^{+} \mathrm{CD} 8^{+} \mathrm{T}$ Cells}

Preclinical study showed that immunotherapy with anti-PD1 treatment increased the prevalence of exhausted $\mathrm{PD} 1^{+} \mathrm{CD} 8^{+} \mathrm{T}$ cells with high mRNA expression of C-X-C motif chemokine receptor 6 (CXCR6) and tumor necrosis factor-alpha (TNF- $\alpha$ ) in the liver of NASH mice, which was associated with impaired immune surveillance and increased incidence of NASH to HCC progression (22). Similar phenotypic and functional $\mathrm{PD} 1^{+} \mathrm{CD} 8^{+}$ $\mathrm{T}$ cells were found in livers from humans with NAFLD/NASH in this report. In addition, both anti-CD8 or anti-TNF plus anti-PD1 antibody treatments can ameliorate liver damage and inflammation and reduce HCC incidence compared to anti-PD1 treatment alone.

\section{CXCR6 ${ }^{+} \mathrm{CD}^{+}+\mathrm{T}$ Cells}

Liver-resident $\mathrm{CXCR}^{+}{ }^{+} \mathrm{CD} 8^{+} \mathrm{T}$ cells were increased in NASH mice fed a CD-HFD, and those $\mathrm{CD}^{+} \mathrm{T}$ cells expressed low activity of the Forkhead box protein O1 (FOXO1) transcription factor caused by high expression of IL-15 (28). In addition, the level of hepatic acetate was increased in $\mathrm{NASH}$ mice, which can cause auto-aggressive liver $\mathrm{CXCR6}^{+}$ $\mathrm{CD}^{+} \mathrm{T}$ cells to damage hepatocytes, resulting in liver injury. Furthermore, $\mathrm{CXCR}^{+}{ }^{\mathrm{CD}} 8^{+} \mathrm{T}$ cells were also shown to increase in human NAFLD/NASH livers, as well as hepatic expression of CXCR6 (28).

\section{Prf1 ${ }^{\text {null }} \mathrm{CD} 8^{+} \mathrm{T}$ Cells}

Perforin (Prf)-deficient mice on an MCD showed an increased accumulation and activation of $\mathrm{CD}^{+} \mathrm{T}$ cells expressing proinflammatory cytokines (e.g., interferon-gamma, or IFN- $\gamma$ ) compared to wild-type (WT) mice, but not $\mathrm{CD}^{+} \mathrm{T}$ cells (29). The increased IFN- $\gamma$ levels are closely associated with liver dysfunction in human patients, including liver fibrosis, cirrhosis, and HCC (30). In contrast, an increase of cell proliferation antigen $\mathrm{Ki} 67^{+} \mathrm{CD}^{+} \mathrm{T}$ cells producing IFN- $\gamma$ in response to sorafenib treatment was associated with improved OS and progression-free survival (31).

\section{Function of CD4 ${ }^{+} \mathrm{T}$ Cells in NAFLD}

Dysregulation of hepatic lipid metabolism in human NAFLD patients and mouse models induced a reduction of liver $\mathrm{CD} 4{ }^{+}$ $\mathrm{T}$ cells $(21,32)$. Fatty liver impairs the immunotherapeutic effects (33), such as RNA vaccine (e.g., M30-RNA vaccine) and antibody-mediated therapy [e.g., anti-OX40 (CD134) antibody]. Feeding a high-fat and high-calorie diet caused the proliferation of human $\mathrm{CD}^{+}$central and effector memory $\mathrm{T}$ cells in immunodeficient mice engrafted with human immune cells (HIL mice) compared to that in mice fed with a chow diet, which was associated with a significant increase of pro-inflammatory cytokines, such as IL-17A and IFN- $\gamma$ (34). In addition, in vivo depletion of human $\mathrm{CD} 4^{+} \mathrm{T}$ cells in those mice can attenuate hepatic inflammation and fibrosis. In summary, these results show that $\mathrm{CD}^{+} \mathrm{T}$ cells play diverse roles in the development of NAFLD, liver fibrosis, and HCC. Thus, clarifying the function of each type of $\mathrm{CD}^{+} \mathrm{T}$ cell is necessary. 
A

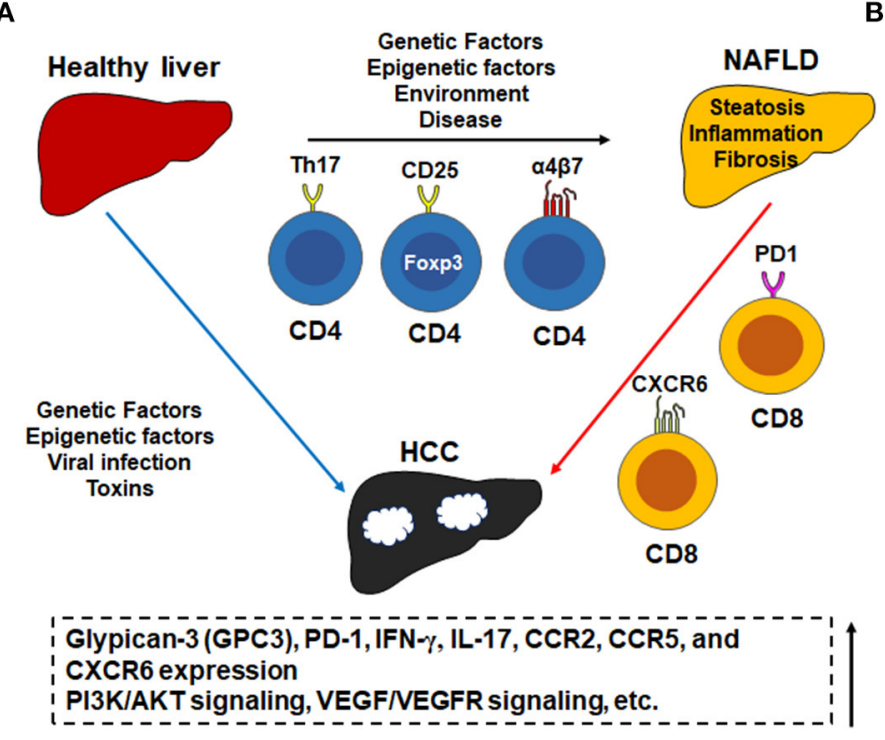

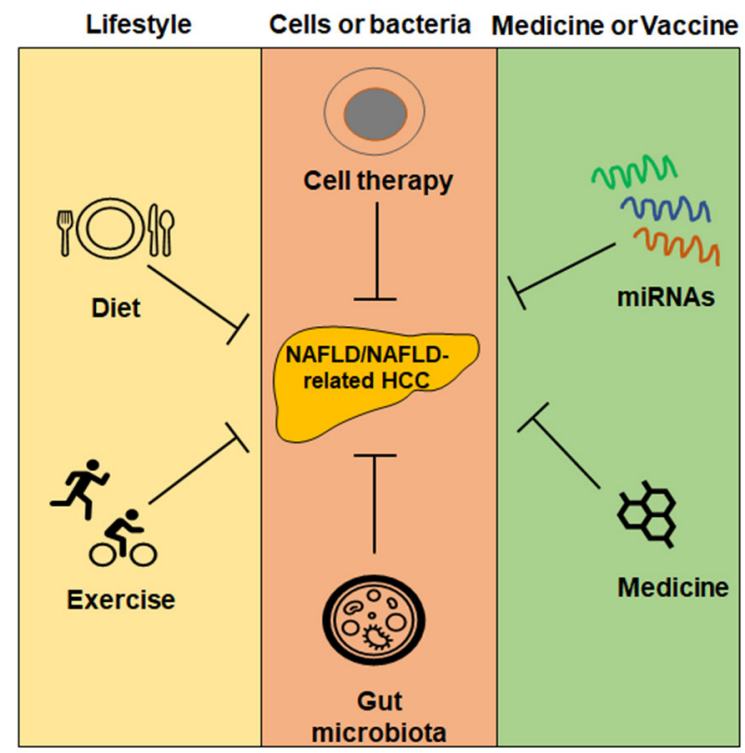

FIGURE 1 | The important role of T cells in the pathogenesis of NAFLD and NAFLD-related HCC and potential treatment options. (A) Some important subtypes of T

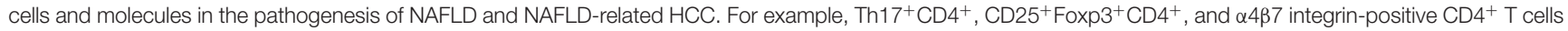
increase in the progression of NAFLD, while PD1 ${ }^{+} \mathrm{CD} 8^{+}$and $\mathrm{CXCR6}{ }^{+} \mathrm{CD} 8^{+}$increase in NAFLD-HCC progression. The change of T cell population is associated with an increase of cytokines such as IL-17a and IFN- $\gamma$ which accompany the progression of NAFLD. (B) The potential treatment options for NAFLD and NAFLD-related HCC include change of lifestyle, cells or bacteria-mediated therapy such as adoptive transfer of T cells, medicines or vaccines such as microRNA-mediated therapy.

\section{$\alpha 4 \beta 7^{+}$CD4 ${ }^{+} \mathrm{T}$ Cells}

Recruitment of integrin $\alpha 4 \beta 7^{+} \mathrm{CD} 4^{+} \mathrm{T}$ cells to the liver was associated with NASH progression in $\mathrm{F}_{11 \mathrm{r}^{-/}}$mice fed with WD, which was correlated with higher expression of its ligand mucosal addressin cell adhesion molecule 1 (MAdCAM-1) (35). Blocking integrin $\alpha 4 \beta 7$ prevented migration of $\mathrm{CD}^{+}{ }^{+} \mathrm{T}$ cells, resulting in a significant decrease in liver inflammation and fibrosis. In addition, ablating $\beta 7$ integrin or MAdCAM-1, as well as $\beta 7$ integrin deficiency, can reduce concanavalin $\mathrm{A}$ (ConA)induced hepatitis in mice, indicating the role of $\beta 7$ integrin in liver injury (36).

\section{Th17 ${ }^{+}$Cells}

In the progression of NAFLD to NASH, hepatic $\mathrm{IL}-17^{+} \mathrm{CD} 4^{+}$ $\mathrm{T}$ (Th17) cells were significantly increased, and the ratio of Th17 or Th2 to $\mathrm{CD} 4{ }^{+} \mathrm{CD} 45 \mathrm{RA}^{+} \mathrm{CD} 25^{++}$resting Tregs (rTregs) was elevated in peripheral blood (37). Imbalance of hepatic Th17/Treg cells was also shown in NAFLD mice fed a HFD (38). The increased frequency of $\mathrm{IL}_{-1} 7^{+}$cells in total $\mathrm{CD} 4^{+} \mathrm{T}$ cells in NASH patients was positively correlated with a higher level of serum concentration of blood endotoxin (LPS) compared to either healthy subjects or non-alcohol fatty liver (NAFL) patients (39).

\section{Treg Cells}

The interaction of Foxp $3^{+} \mathrm{CD} 25^{+} \mathrm{CD} 4^{+} \mathrm{T}$ cells (Tregs) with other immune cells and hepatocytes plays a critical role in liver homeostasis and pathogenesis. Hepatocytes can engulf $\mathrm{CD}^{+} \mathrm{T}$ cells, preferable for Tregs, during liver inflammation to control T cell population, known as enclysis (40). The frequency of $\mathrm{CD} 25^{+} \mathrm{CD} 45^{+} \mathrm{CD} 4{ }^{+} \mathrm{T}$ cells was increased in PBMCs of human NAFLD patients with advanced liver fibrosis, while the $\mathrm{PD}^{+}{ }^{+} \mathrm{CD} 4{ }^{+} \mathrm{T}$ cells were decreased (41), which were significantly and negatively correlated with the ratio of serum fatty acid composition $(44,45)$.

Moreover, there are other subtypes of T cells that were found to be associated with the progression of NAFLD, such as V $\delta 2 \mathrm{~T}$ cells (42) and $\gamma \delta$ T cells (43).

\section{Function of CD4 ${ }^{+} \mathrm{T}$ Cells in NAFLD-Related HCC Treg Cells}

Transcription factor Foxp3 can suppress glycolysis and induce oxidative phosphorylation to change metabolic profiles of Tregs to survive in low-glucose and high lactate environments (44). The proliferation of Tregs can suppress the function of cytotoxic $\mathrm{CD}^{+} \mathrm{T}$ cells against liver tumor cells, resulting in the progression of HCC both in mouse models and in human patients (45). A high ratio of effector $\mathrm{CD} 4^{+} \mathrm{T}$ cells/Treg showed a good prognostic for human HCC (31).

\section{Th17 Cells}

Th17 cells and the expression of IL-17a were positively associated with human fatty liver-associated HCC (46). In vitro study showed that macrophages are required to mediate IL-17 expression in naive $\mathrm{CD}^{+}{ }^{+} \mathrm{T}$ cells through LPS/Tolllike receptor 4 (TLR4) signaling. Furthermore, intra-tumoral infiltration of Th17 cells promoted tumor growth via promoting 
angiogenesis and predicted a poor OS in HCC patients (47). In addition to inducing angiogenic factors (e.g., vascular endothelial growth factor/VEGF and prostaglandin E2/PGE2), Th17 cells can activate oncogenic IL-6/Stat3 signaling to enhance tumor growth (48).

\section{Function of Double-Negative T Cells in NAFLD-Related HCC}

Double-negative $\mathrm{T}$ cells (DNT) defined by $\mathrm{T}$-cell receptor (TCR) $\alpha \beta^{+} \mathrm{CD}^{+}{ }^{+} \mathrm{CD} 4^{-} \mathrm{CD} 8^{-} \mathrm{T}$ cells and consisting of $1-$ $3 \%$ of peripheral $\mathrm{T}$ lymphocytes in mice and humans have been shown to play multiple roles in immune responses (49). Adoptive transfer of $\mathrm{CD}^{+} \mathrm{T}$ cells converted DNT was shown to reduce liver inflammation and fat accumulation inducing factors for NASH, by suppressing the infiltration of Th17 cells and M1 macrophages (8). Double-negative T cells can also inhibit the function of effector $\mathrm{CD}^{+} \mathrm{T}$ cells by impairing glucose metabolism and inhibiting mTOR signaling and the expression of inflammatory cytokines IL-17a and IFN$\gamma$ (50). Furthermore, DNT was shown to be higher in nontumor-infiltrating lymphocytes compared to tumor-infiltrating lymphocytes in human HCC (51).

\section{POTENTIAL TREATMENT OPTIONS FOR NAFLD-RELATED HCC BY TARGETING ON T CELLS}

Currently, there are some approved first- and second-line treatment options for HCC, which may be also applied in NAFLD-related HCC treatment. In 2008, sorafenib, a multikinase inhibitor against VEGF receptor (VEGFR), plateletderived growth factor receptor (PDGFR), and RAF kinases (serine/threonine protein kinases), is the first approved systemic therapy by the U.S. FDA for patients with unresectable HCC (52). In 2018, lenvatinib, a multiple kinase inhibitor against the VEGFR1, VEGFR2, and VEGFR3 kinases, was approved by FDA for systemic treatment for unresectable advanced HCC (53). In 2020, PD-L1 inhibitor atezolizumab was approved by FDA in combination with bevacizumab (anti-VEGF monoclonal antibody) for adult patients with unresectable locally advanced or metastatic HCC without prior systemic therapy (54). In addition, there are some combined treatments such as nivolumab (antiPD-1 monoclonal antibody) and ipilimumab (anti-cytotoxic Tlymphocyte-associated protein 4/CTLA4 monoclonal antibody) that may approve the outcomes (55). Here, we also review some treatment options by targeting T cells (Figure 1).

\section{T Cell-Mediated Treatment}

A clinical trial shows that treatment with sorafenib, a protein kinase inhibitor, can increase $\mathrm{Ki} 67^{+} \mathrm{CD} 8^{+} \mathrm{T}$ cells producing IFN$\gamma$ to improve progression-free survival and OS of human HCC patients (31). The VEGF/VEGFR signaling was involved in this effect, evidenced by improved sorafenib in combination with VEGFR antagonism (31).

A decrease of Tregs in visceral adipose tissue (VAT) is positively associated with NASH progression (56). Adoptively transfer (ACT) of Tregs from spleens of healthy mice to mice with diet-induced hepatic steatosis promoted liver steatosis with an increase of Tregs in VAT and a decrease of Th1 cells in various tissues (57). Adoptively transfer of Tregs did not impact other metabolic and histologic changes. Recently, a phase I clinical trial showed the initial safety profile and effect of chimeric antigen receptor (CAR)-glypican-3 (GPC3) Tcell therapy for patients with advanced HCC (58). Those CAR $\mathrm{T}$ cells include a humanized anti-GPC3 single-chain variable fragment, $\mathrm{CD} 8 \alpha$ hinge domain, $\mathrm{CD} 8 \alpha$ transmembrane domain, $\mathrm{CD} 28$ intracellular domain, and $\mathrm{CD} 3 \zeta$ intracellular signaling domain. There are some recruiting clinical trials for investigating GPC3-targeted CAR-T Cell for treating HCC, such as trials NCT03198546 and NCT04121273.

\section{Gut Microbiota-Mediated Therapy}

Gut microbiota has been shown to play vital roles in human liver diseases (59), through modulating secondary bile acids (BAs), activating TLRs, and influencing the function of immune checkpoint inhibitors (ICIs). For example, gut microbial extracts from NAFLD-HCC patients dramatically suppressed $\mathrm{CD}^{+} \mathrm{T}$ cells and $\mathrm{B}$ cells in PBMCs from non-NAFLD healthy people compared to bacterial extract from non-NAFLD controls, but significantly increased the proliferation of $\mathrm{CD}^{+} \mathrm{CD}^{+} \mathrm{CD} 25^{+} \mathrm{Foxp}^{+}$Tregs, inducing an immunosuppressive phenomenon (20). Fecal microbiota transplantation (FMT) from proper donors can restore gut microbiota disorder and ameliorate D-galactosamineinduced liver injury in $\mathrm{BALB} / \mathrm{c}$ mice, via downregulating the expression of IL-17a, TNF- $\alpha$, and transforming growth factor $-\beta$ (TGF- $\beta$ ) and upregulating the expression of IL-10 and IL-22 (60).

\section{miRNA-Mediated Treatment}

Overexpression of microRNA-195 (miR-195) can improve the balance of Th17/Treg via regulating CD40 expression in rat liver tissues, accompanying decrease of serum level of proinflammatory cytokines (e.g., TNF- $\alpha$ ), total cholesterol (TC) and triglyceride (TG), liver injury markers aspartate transaminase (AST), and alanine aminotransferase (ALT) (61). In addition, hepatocyte-specific overexpression of miR-34a promoted high cholesterol and fructose (HFCF) fat dietinduced NAFLD in mice, while pharmaceutical suppression of miR-34a can reverse NAFLD progression (62). miR26a can inhibit hepatic expression of IL-17 and IL-6, as lentiviral vector delivered miR-26a treatment significantly decreased total liver weight, liver deposition of TG, and serum ALT concentration compared lentiviral control-treated mice, accompanying decreased infiltration of $\gamma \delta \mathrm{T}$ cells, and granulocyte-differentiation antigen-1 $(\mathrm{Gr}-1)^{+}$cells and $\mathrm{CD}_{11 \mathrm{~b}^{+}}$cells (63). In addition, Escutia-Gutiérrez et al. reported that miRNAs such as miR-21a-5p, miR-34a-5p, miR-122-5p, and miR-103-3p were increased expression of in livers of MAFLD/NASH (64), the potential targets for HCC treatment. 


\section{Chemokine or Cytokine-Mediated Treatment}

Treatment with C-C chemokine receptor (CCR)2 antagonist inhibited tumor-infiltrating macrophage (TAMs)-mediated immunosuppression and increased $\mathrm{CD}^{+} \mathrm{T}$ cells in liver cancer (65). In addition, this antagonist improved the therapeutic effect of sorafenib via enhancing tumor necrosis and apoptosis. CCR5/CCL5 signaling pathway plays a critical in the development of HCC in chronic liver disease both in mice and humans (66-68), as a potential treatment target for HCC. Moreover, injection of WSX1 (IL-27 receptor $\alpha$ ) can significantly suppress the HCC growth by suppressing PD-L1 expression on tumor cells via blocking phosphoinositide 3kinase delta $(\mathrm{PI} 3 \mathrm{~K} \delta) /$ protein kinase B $(\mathrm{AKT}) /$ glycogen synthase kinase-3 $\beta$ (GSK3 $\beta$ ) pathway to release the cytotoxic effect of $\mathrm{CD}^{+} \mathrm{T}$ cells (69). Combined therapy with regorafenib and anti-PD-1 increased the filtration and activation of $\mathrm{CXCR}^{+}{ }^{+} \mathrm{CD}^{+}{ }^{+} \mathrm{T}$ cells via increasing CXCL10 expression in tumors, resulting in inhibition of HCC growth (70). Therefore, modulating chemokines, chemokine receptors, and cytokines can improve anti-tumor immunity to inhibit tumor progression.

\section{DISCUSSION}

Obesity and NAFLD are closely linked with each other. NAFLD patients with medium-high risk obesity with body mass index (BMI) $>35 \mathrm{~kg} / \mathrm{m}^{2}$ showed poor response to hepatitis B virus (HBV) vaccine (71). In addition, hepatitis $B$ surface antigenspecific $\mathrm{CD}^{+} \mathrm{T}$ cells showed significantly less proliferation in PBMCs of high-risk obesity NAFLD patients compared to that in low-risk obesity NAFLD subjects. Fatty liver disease also is a serious issue for obese children. Lipid metabolism is one of the major contributing factors for NAFLD (72). Fat metabolism

\section{REFERENCES}

1. Estes C, Anstee QM, Arias-Loste MT, Bantel H, Bellentani S, Caballeria J, et al. Modeling NAFLD disease burden in China, France, Germany, Italy, Japan, Spain, United Kingdom, and United States for the period 2016-2030. J Hepatol. (2018) 69:896-904. doi: 10.1016/j.jhep.2018. 05.036

2. Yang M. Zhang, C. G protein-coupled receptors as potential targets for nonalcoholic fatty liver disease treatment. World J Gastroenterol. (2021) 27:677-91. doi: 10.3748/wjg.v27.i8.677

3. Wong C, Lee MH, Yaow CYL, Chin YH, Goh XL, Ng CH, et al. Glucagonlike peptide-1 receptor agonists for non-alcoholic fatty liver disease in type 2 diabetes: a meta-analysis. Front Endocrinol (Lausanne). (2021) 12:609110. doi: 10.3389/fendo.2021.609110

4. Eslam M, Newsome PN, Sarin SK, Anstee QM, Targher G, Romero-Gomez $\mathrm{M}$, et al. A new definition for metabolic dysfunction-associated fatty liver disease: an international expert consensus statement. J Hepatol. (2020) 73:202-9. doi: 10.1016/j.jhep.2020.03.039

5. Eslam M, Sanyal AJ, George J. MAFLD: a consensus-driven proposed nomenclature for metabolic associated fatty liver disease. Gastroenterology. (2020) 158:1999.e1-2014.e1. doi: 10.1053/j.gastro.2019.11.312

6. Neuschwander-Tetri BA. Therapeutic landscape for NAFLD in 2020. Gastroenterology. (2020) 158:1984.e3-98.e3. doi: 10.1053/j.gastro.2020.01.051 modulates T cell profiles in the liver of NAFLD subjects to impact NAFLD-HCC progression. New technologies (e.g., siRNA-seq) improve our understanding of the pathogenesis of NAFLD. Each subtype of $\mathrm{T}$ cells is shown to play different roles in NAFLD progression, such as $\mathrm{TCR} \alpha \beta^{+} \mathrm{CD} 3^{+} \mathrm{CD} 4^{-} \mathrm{CD} 8^{-}$cells and $\mathrm{CXCR}^{+}{ }^{+} \mathrm{CD}^{+}$or $\mathrm{PD}^{+}{ }^{+} \mathrm{CXCR}^{+}{ }^{+} \mathrm{CD} 8^{+} \mathrm{T}$ cells. Targeting those $\mathrm{T}$ cells by orchestrating gut microbiota, treatment of miRNAs, adoptive transfer of $\mathrm{T}$ cells, and modulating the expression of small molecules are potential treatment options against NAFLD and NAFLD-HCC progression. In addition, energy restriction is a method to reduce BMI and ameliorate fatty liver disease, which may bring new health concerns. Supplement of lycopene-rich tomato juice to obese children can improve calorie-restricted regimen-induced impairment of glycolysis and mitochondrial metabolism in $\mathrm{T}$ cells to enhance their immune surveillance function (73).

T cell populations vary during the development of NAFLDrelated HCC, including the changes in subtype and function. For example, Tregs in the early stage of NAFLD/NASH can suppress liver inflammatory function, but in the HCC stage, they can inhibit effector $\mathrm{T}$ cell function to suppress tumor progression. Therefore, manipulation of $\mathrm{T}$ cell function or population is dependent on the stage of liver disease and microenvironment. In addition, proteomic analysis of NAFLD-HCC infiltrating T cells is awaited to explore the functional proteins to modify those $\mathrm{T}$ cell functions except PD-1 and CXCR6. Overall, T cells play a critical role in metabolic fatty liver diseases to HCC progression, and targeting them may provide a novel treatment.

\section{AUTHOR CONTRIBUTIONS}

$\mathrm{CZ}$ and MY conceived the opinion and wrote the manuscript. All authors contributed to the article and approved the submitted version.

7. Cairoli V, De Matteo E, Rios D, Lezama C, Galoppo M, Casciato $\mathrm{P}$, et al. Hepatic lymphocytes involved in the pathogenesis of pediatric and adult non-alcoholic fatty liver disease. Sci Rep. (2021) 11:5129. doi: 10.1038/s41598-021-84674-Z

8. Sun G, Zhao X, Li M, Zhang C, Jin H, Li C, et al. CD4 derived double negative $\mathrm{T}$ cells prevent the development and progression of nonalcoholic steatohepatitis. Nat Commun. (2021) 12:650. doi: 10.1038/s41467-021-20941-x

9. Antonucci L, Porcu C, Timperi E, Santini SJ, Iannucci G, Balsano C. Circulating neutrophils of nonalcoholic steatohepatitis patients show an activated phenotype and suppress T lymphocytes activity. J Immunol Res. (2020) 2020:4570219. doi: 10.1155/2020/4570219

10. Barrow F, Khan S, Fredrickson G, Wang H, Dietsche K, Parthiban P, et al. Microbiota-driven activation of intrahepatic B cells aggravates nonalcoholic steatohepatitis through innate and adaptive signaling. Hepatology. (2021) 74:704-22. doi: 10.1002/hep.31755

11. Ramachandran P, Matchett KP, Dobie R, Wilson-Kanamori JR, Henderson, NC. Single-cell technologies in hepatology: new insights into liver biology and disease pathogenesis. Nat Rev Gastroenterol Hepatol. (2020) 17:45772. doi: $10.1038 / \mathrm{s} 41575-020-0304-\mathrm{x}$

12. Zheng C, Zheng L, Yoo JK, Guo H, Zhang Y, Guo X, et al. Landscape of infiltrating $\mathrm{T}$ cells in liver cancer revealed by single-cell sequencing. Cell. (2017) 169:1342.e16-56.e16. doi: 10.1016/j.cell.2017.05.035 
13. Myers S, Neyroud-Caspar I, Spahr L, Gkouvatsos K, Fournier E, Giostra E, et al. NAFLD and MAFLD as emerging causes of HCC: a populational study. JHEP Rep. (2021) 3:100231. doi: 10.1016/j.jhepr.2021.100231

14. Valenti L, Al-Serri A, Daly AK, Galmozzi E, Rametta R, Dongiovanni P, et al. Homozygosity for the patatin-like phospholipase-3/adiponutrin I148M polymorphism influences liver fibrosis in patients with nonalcoholic fatty liver disease. Hepatology. (2010) 51:1209-17. doi: 10.1002/hep.23622

15. Tian Y, Wong VW, Wong GL, Yang W, Sun H, Shen J, et al. Histone deacetylase HDAC8 promotes insulin resistance and $\beta$-catenin activation in NAFLD-associated hepatocellular carcinoma. Cancer Res. (2015) 75:480316. doi: 10.1158/0008-5472.Can-14-3786

16. Eldafashi N, Darlay R, Shukla R, McCain MV, Watson R, Liu YL, et al. A PDCD1 role in the genetic predisposition to NAFLD-HCC? Cancers (Basel). (2021) 13:1412. doi: 10.3390/cancers13061412

17. Newberry EP, Hall Z, Xie Y, Molitor EA, Bayguinov PO, Strout GW, et al. Liver specific deletion of mouse Tm6sf2 promotes steatosis, fibrosis and hepatocellular cancer. Hepatology. (2021) 74:1203-19. doi: 10.1002/hep.31771

18. Zhang C, Yang, M. The emerging factors and treatment options for NAFLD-related hepatocellular carcinoma. Cancers (Basel). (2021) 13:3740. doi: 10.3390/cancers13153740

19. Onorato AM, Fiore E, Bayo J, Casali C, Fernandez-Tomé M, Rodríguez M, et al. SPARC inhibition accelerates NAFLD-associated hepatocellular carcinoma development by dysregulating hepatic lipid metabolism. Liver Int. (2021) 41:1677-93. doi: 10.1111/liv.14857

20. Behary J, Amorim N, Jiang XT, Raposo A, Gong L, McGovern E, et al. Gut microbiota impact on the peripheral immune response in non-alcoholic fatty liver disease related hepatocellular carcinoma. Nat Commun. (2021) 12:187. doi: 10.1038/s41467-020-20422-7

21. Ma C, Kesarwala AH, Eggert T, Medina-Echeverz J, Kleiner DE, Jin P, et al. NAFLD causes selective CD4(+) T lymphocyte loss and promotes hepatocarcinogenesis. Nature. (2016) 531:253-7. doi: 10.1038/nature16969

22. Pfister D, Núñez NG, Pinyol R, Govaere O, Pinter M, Szydlowska M, et al. NASH limits anti-tumour surveillance in immunotherapy-treated HCC Nature. (2021) 592:450-6. doi: 10.1038/s41586-021-03362-0

23. Wolf MJ, Adili A, Piotrowitz K, Abdullah Z, Boege Y, Stemmer K, et al. Metabolic activation of intrahepatic CD8+ T cells and NKT cells causes nonalcoholic steatohepatitis and liver cancer via cross-talk with hepatocytes. Cancer Cell. (2014) 26:549-64. doi: 10.1016/j.ccell.2014.09.003

24. Breuer DA, Pacheco MC, Washington MK, Montgomery SA, Hasty AH, Kennedy AJ. CD8(+) T cells regulate liver injury in obesity-related nonalcoholic fatty liver disease. Am J Physiol Gastrointest Liver Physiol. (2020) 318:G211-24. doi: 10.1152/ajpgi.00040.2019

25. Shakiba E, Ramezani M, Sadeghi, M. Evaluation of serum interleukin-10 levels in hepatocellular carcinoma patients: a systematic review and meta-analysis. Clin Exp Hepatol. (2018) 4:35-40. doi: 10.5114/ceh.2018.73484

26. Muñoz-Durango $\mathrm{N}$, Arrese $\mathrm{M}$, Hernández A, Jara E, Kalergis AM, Cabrera D. A mineralocorticoid receptor deficiency in myeloid cells reduces liver steatosis by impairing activation of $\mathrm{CD} 8(+) \mathrm{T}$ cells in a nonalcoholic steatohepatitis mouse model. Front Immunol. (2020) 11:563434. doi: 10.3389/fimmu.2020.563434

27. Ringel AE, Drijvers JM, Baker GJ, Catozzi A, García-Cañaveras JC, Gassaway BM, et al. Obesity shapes metabolism in the tumor microenvironment to suppress anti-tumor immunity. Cell. (2020) 183:1848.e26-66.e26. doi: 10.1016/j.cell.2020.11.009

28. Dudek M, Pfister D, Donakonda S, Filpe P, Schneider A, Laschinger M, et al. Auto-aggressive CXCR6(+) CD8 T cells cause liver immune pathology in NASH. Nature. (2021) 592:444-9. doi: 10.1038/s41586-021-03233-8

29. Wang T, Sun G, Wang Y, Li S, Zhao X, Zhang C, et al. The immunoregulatory effects of CD8 T-cell-derived perforin on diet-induced nonalcoholic steatohepatitis. FASEB J. (2019) 33:8490-503. doi: 10.1096/fj.20180 2534RR

30. Attallah AM, El-Far M, Zahran F, Shiha GE, Farid K, Omran MM, et al. Interferon-gamma is associated with hepatic dysfunction in fibrosis, cirrhosis, and hepatocellular carcinoma. J Immunoassay Immunochem. (2016) 37:597610. doi: 10.1080/15321819.2016.1179646

31. Kalathil SG, Hutson A, Barbi J, Iyer R, Thanavala, Y. Augmentation of IFN- $\gamma+$ CD8 + T cell responses correlates with survival of HCC patients on sorafenib therapy. JCI Insight. (2019) 4:e130116. doi: 10.1172/jci.insight.130116
32. Coia H, Ma N, Hou Y, Permaul E, Berry DL, Cruz MI, et al. Theaphenon E prevents fatty liver disease and increases CD4+ T cell survival in mice fed a high-fat diet. Clin Nutr. (2021) 40:110-9. doi: 10.1016/j.clnu.2020.04.033

33. Heinrich B, Brown ZJ, Diggs LP, Vormehr M, Ma C, Subramanyam $\mathrm{V}$, et al. Steatohepatitis impairs T-cell-directed immunotherapies against liver tumors in mice. Gastroenterology. (2021) 160:331.e645.e6. doi: 10.1053/j.gastro.2020.09.031

34. Her Z, Tan JHL, Lim YS, Tan SY, Chan XY, Tan WWS, et al. CD4(+) $\mathrm{T}$ cells mediate the development of liver fibrosis in high fat diet-induced NAFLD in humanized mice. Front Immunol. (2020) 11:580968. doi: 10.3389/fimmu.2020.580968

35. Rai RP, Liu Y, Iyer SS, Liu S, Gupta B, Desai C, et al. Blocking integrin $\alpha(4) \beta(7)$ mediated CD4 T cell recruitment to the intestine and liver protects mice from western diet-induced non-alcoholic steatohepatitis. J Hepatol. (2020) 73:1013-22. doi: 10.1016/j.jhep.2020.05.047

36. Schippers A, Hübel J, Heymann F, Clahsen T, Eswaran S, Schlepütz S, et al. MAdCAM-1/ $\alpha 4 \beta 7$ integrin-mediated lymphocyte/endothelium interactions exacerbate acute immune-mediated hepatitis in mice. Cell Mol Gastroenterol Hepatol. (2021) 11:1227.e1-50.e1. doi: 10.1016/j.jcmgh.2020.12.003

37. Rau M, Schilling AK, Meertens J, Hering I, Weiss J, Jurowich C, et al. Progression from nonalcoholic fatty liver to nonalcoholic steatohepatitis is marked by a higher frequency of Th17 Cells in the liver and an increased Th17/resting regulatory $\mathrm{T}$ cell ratio in peripheral blood and in the liver. $J$ Immunol. (2016) 196:97-105. doi: 10.4049/jimmunol.1501175

38. He B, Wu L, Xie W, Shao Y, Jiang J, Zhao Z, et al. The imbalance of Th17/Treg cells is involved in the progression of nonalcoholic fatty liver disease in mice. BMC Immunol. (2017) 18:33. doi: 10.1186/s12865-017-0215-y

39. Wang X, Ji D, Zhu B, Jiang S, Han L, Wang Y, et al. Contribution of endotoxin to Th17 bias in patients with non-alcoholic steatohepatitis. Microb Pathog. (2020) 142:104009. doi: 10.1016/j.micpath.2020.104009

40. Davies SP, Reynolds GM, Wilkinson AL, Li X, Rose R, Leekha M, et al. Hepatocytes delete regulatory T cells by enclysis, a CD4(+) T cell engulfment process. Cell Rep. (2019) 29:1610.e4-20.e4. doi: 10.1016/j.celrep.2019.09.068

41. Seike T, Mizukoshi E, Yamada K, Okada H, Kitahara M, Yamashita $\mathrm{T}$, et al. Fatty acid-driven modifications in T-cell profiles in nonalcoholic fatty liver disease patients. J Gastroenterol. (2020) 55:701-11. doi: 10.1007/s00535-020-01679-7

42. Diedrich T, Kummer S, Galante A, Drolz A, Schlicker V, Lohse AW, et al. Characterization of the immune cell landscape of patients with NAFLD. PLoS ONE. (2020) 15:e0230307. doi: 10.1371/journal.pone.0230307

43. Torres-Hernandez A, Wang W, Nikiforov Y, Tejada K, Torres L, Kalabin A, et al. $\gamma \delta \mathrm{T}$ cells promote steatohepatitis by orchestrating innate and adaptive immune programming. Hepatology. (2020) 71:47794. doi: 10.1002/hep.30952

44. Angelin A, Gil-de-Gómez L, Dahiya S, Jiao J, Guo L, Levine $\mathrm{MH}$, et al. Foxp3 reprograms $\mathrm{T}$ cell metabolism to function in low-glucose, high-lactate environments. Cell Metab. (2017) 25:1282.e7-93.e7. doi: 10.1016/j.cmet.2016.12.018

45. Jiang R, Tang J, Chen Y, Deng L, Ji J, Xie Y, et al. The long noncoding RNA lnc-EGFR stimulates T-regulatory cells differentiation thus promoting hepatocellular carcinoma immune evasion. Nat Commun. (2017) 8:15129. doi: $10.1038 /$ ncomms 15129

46. Gomes AL, Teijeiro A, Burén S, Tummala KS, Yilmaz M, Waisman A, et al. Metabolic inflammation-associated IL-17A causes non-alcoholic steatohepatitis and hepatocellular carcinoma. Cancer Cell. (2016) 30:16175. doi: 10.1016/j.ccell.2016.05.020

47. Zhang JP, Yan J, Xu J, Pang XH, Chen MS, Li L, et al. Increased intratumoral IL-17-producing cells correlate with poor survival in hepatocellular carcinoma patients. J Hepatol. (2009) 50:980-9. doi: 10.1016/j.jhep.2008.12.033

48. Ye J, Livergood RS, Peng G. The role and regulation of human Th17 cells in tumor immunity. Am J Pathol. (2013) 182:10-20. doi: 10.1016/j.ajpath.2012.08.041

49. Tian D, Yang L, Wang S, Zhu Y, Shi W, Zhang C, et al. Double negative $\mathrm{T}$ cells mediate Lag3-dependent antigen-specific protection in allergic asthma. Nat Commun. (2019) 10:4246. doi: 10.1038/s41467-01912243-0

50. Haug T, Aigner M, Peuser MM, Strobl CD, Hildner K, Mougiakakos D, et al. Human double-negative regulatory T-Cells induce a metabolic and functional 
switch in effector T-cells by suppressing mTOR activity. Front Immunol. (2019) 10:883. doi: 10.3389/fimmu.2019.00883

51. Di Blasi D, Boldanova T, Mori L, Terracciano L, Heim MH, De Libero, G. Unique T-cell populations define immune-inflamed hepatocellular carcinoma. Cell Mol Gastroenterol Hepatol. (2020) 9:195-218. doi: 10.1016/j.jcmgh.2019.08.004

52. Kane RC, Farrell AT, Madabushi R, Booth B, Chattopadhyay S, Sridhara R, et al. Sorafenib for the treatment of unresectable hepatocellular carcinoma. Oncologist. (2009) 14:95-100. doi: 10.1634/theoncologist.2008-0185

53. Kudo M, Finn RS, Qin S, Han KH, Ikeda K, Piscaglia F, et al. Lenvatinib versus sorafenib in first-line treatment of patients with unresectable hepatocellular carcinoma: a randomised phase 3 non-inferiority trial. Lancet. (2018) 391:1163-73. doi: 10.1016/s0140-6736(18)30207-1

54. Casak SJ, Donoghue M, Fashoyin-Aje L, Jiang X, Rodriguez L, Shen YL, et al. FDA approval summary: atezolizumab plus bevacizumab for the treatment of patients with advanced unresectable or metastatic hepatocellular carcinoma. Clin Cancer Res. (2021) 27:1836-41. doi: 10.1158/1078-0432.Ccr-20-3407

55. Saung MT, Pelosof L, Casak S, Donoghue M, Lemery S, Yuan M, et al. FDA approval summary: nivolumab plus ipilimumab for the treatment of patients with hepatocellular carcinoma previously treated with sorafenib. Oncologist. (2021) 26:797-806. doi: 10.1002/onco.13819

56. Van Herck MA, Vonghia L, Kwanten WJ, Julé Y, Vanwolleghem T, Ebo DG, et al. Diet reversal and immune modulation show key role for liver and adipose tissue T cells in murine nonalcoholic steatohepatitis. Cell Mol Gastroenterol Hepatol. (2020) 10:467-90. doi: 10.1016/j.jcmgh.2020.04.010

57. Van Herck MA, Vonghia L, Kwanten WJ, Vanwolleghem T, Ebo DG, Michielsen PP, et al. Adoptive cell transfer of regulatory T cells exacerbates hepatic steatosis in high-fat high-fructose diet-fed mice. Front Immunol. (2020) 11:1711. doi: 10.3389/fimmu.2020.01711

58. Shi D, Shi Y, Kaseb AO, Qi X, Zhang Y, Chi J, et al. Chimeric Antigen receptor-glypican-3 T-cell therapy for advanced hepatocellular carcinoma: results of phase I trials. Clin Cancer Res. (2020) 26:397989. doi: 10.1158/1078-0432.Ccr-19-3259

59. Zhang C, Yang M. Ericsson, AC. The potential gut microbiotamediated treatment options for liver cancer. Front Oncol. (2020) 10:524205. doi: 10.3389/fonc.2020.524205

60. Liu Y, Fan L, Cheng Z, Yu L, Cong S, Hu Y, et al. Fecal transplantation alleviates acute liver injury in mice through regulating Treg/Th17 cytokines balance. Sci Rep. (2021) 11:1611. doi: 10.1038/s41598-021-81263-y

61. Li Y, Jiang HT, Han LB, Xiao L, Gan JH. MiR-195 regulates CD40 to maintain Th17/Treg balance in rats with non-alcoholic fatty liver disease. Biomed Pharmacother. (2020) 124:109930. doi: 10.1016/j.biopha.2020.109930

62. Xu Y, Zhu Y, Hu S, Pan X, Bawa FC, Wang HH, et al. Hepatocyte miR-34a is a key regulator in the development and progression of non-alcoholic fatty liver disease. Mol Metab. (2021) 2021:101244. doi: 10.1016/j.molmet.2021.101244

63. He Q, Li F, Li J, Li R, Zhan G, Li G, et al. MicroRNA-26a-interleukin (IL)-6IL-17 axis regulates the development of non-alcoholic fatty liver disease in a murine model. Clin Exp Immunol. (2017) 187:174-84. doi: 10.1111/cei.12838

64. Escutia-Gutiérrez R, Rodríguez-Sanabria JS, Monraz-Méndez CA, GarcíaBañuelos J, Santos-García A, Sandoval-Rodríguez A, et al. Pirfenidone modifies hepatic miRNAs expression in a model of MAFLD/NASH. Sci Rep. (2021) 11:11709. doi: 10.1038/s41598-021-91187-2
65. Yao W, Ba Q, Li X, Li H, Zhang S, Yuan Y, et al. A natural CCR2 antagonist relieves tumor-associated macrophage-mediated immunosuppression to produce a therapeutic effect for liver cancer. EBio Med. (2017) 22:5867. doi: 10.1016/j.ebiom.2017.07.014

66. Mohs A, Kuttkat N, Reißing J, Zimmermann HW, Sonntag R, Proudfoot A, et al. Functional role of CCL5/RANTES for HCC progression during chronic liver disease. J Hepatol. (2017) 66:743-53. doi: 10.1016/j.jhep.2016.12.011

67. Barashi N, Weiss ID, Wald O, Wald H, Beider K, Abraham M, et al. Inflammation-induced hepatocellular carcinoma is dependent on CCR5 in mice. Hepatology. (2013) 58:1021-30. doi: 10.1002/hep.26403

68. Singh SK, Mishra MK, Rivers BM, Gordetsky JB, Bae S, Singh R. Biological and clinical significance of the CCR5/CCL5 axis in hepatocellular carcinoma. Cancers (Basel). (2020) 12:883. doi: 10.3390/cancers12040883

69. Wu M, Xia X, Hu J, Fowlkes NW, Li, S. WSX1 act as a tumor suppressor in hepatocellular carcinoma by downregulating neoplastic PD-L1 expression. Nat Commun. (2021) 12:3500. doi: 10.1038/s41467-021-23864-9

70. Shigeta K, Matsui A, Kikuchi H, Klein S, Mamessier E, Chen IX, et al. Regorafenib combined with PD1 blockade increases CD8 T-cell infiltration by inducing CXCL10 expression in hepatocellular carcinoma. J Immunother Cancer. (2020) 8:e001435. doi: 10.1136/jitc-2020-001435

71. Joshi SS, Davis RP, Ma MM, Tam E, Cooper CL, Ramji A, et al. Reduced immune responses to hepatitis B primary vaccination in obese individuals with nonalcoholic fatty liver disease (NAFLD). NPJ Vaccines. (2021) 6:9. doi: 10.1038/s41541-020-00266-4

72. Kumar S, Verma AK, Rani R, Sharma A, Wang J, Shah SA, et al. Hepatic deficiency of augmenter of liver regeneration predisposes to nonalcoholic steatohepatitis and fibrosis. Hepatology. (2020) 72:1586604. doi: 10.1002/hep.31167

73. Negri R, Trinchese G, Carbone F, Caprio MG, Stanzione G, di Scala C, et al. Randomised clinical trial: calorie restriction regimen with tomato juice supplementation ameliorates oxidative stress and preserves a proper immune surveillance modulating mitochondrial bioenergetics of T-lymphocytes in obese children affected by non-alcoholic fatty liver disease (NAFLD). J Clin Med. (2020) 9:141. doi: 10.3390/jcm9010141

Conflict of Interest: The authors declare that the research was conducted in the absence of any commercial or financial relationships that could be construed as a potential conflict of interest.

Publisher's Note: All claims expressed in this article are solely those of the authors and do not necessarily represent those of their affiliated organizations, or those of the publisher, the editors and the reviewers. Any product that may be evaluated in this article, or claim that may be made by its manufacturer, is not guaranteed or endorsed by the publisher.

Copyright () 2021 Zhang and Yang. This is an open-access article distributed under the terms of the Creative Commons Attribution License (CC BY). The use, distribution or reproduction in other forums is permitted, provided the original author(s) and the copyright owner(s) are credited and that the original publication in this journal is cited, in accordance with accepted academic practice. No use, distribution or reproduction is permitted which does not comply with these terms. 